\title{
Erratum to: Observed and Modelled Convective Mixing-Layer Height at Dome C, Antarctica
}

\author{
Giampietro Casasanta • Ilaria Pietroni · Igor Petenko • \\ Stefania Argentini
}

Published online: 7 August 2014

C) Springer Science+Business Media Dordrecht 2014

\section{Erratum to: Boundary-Layer Meteorol (2014) 151:597-608 DOI 10.1007/s10546-014-9907-5}

We have discovered a calculation error in the evaluation of the history scale $Q$ represented by Eq. 3 (Sect. 4.2). We apologise for any confusion or inconvenience that may have arisen. The miscalculation does not affect the general performance of the diagnostic relation proposed in the same section, so that the conclusions remain almost unchanged.

After the correction, the values of $\alpha$ (Eq. 4) and of the determination coefficient $\left(R^{2}\right)$ retrieved by the linear regression showed in Fig. 8 become $11.20 \pm 0.30$ and 0.86 , respectively. The corrected values of the parameters listed in the last column (Diagnost relation) of Table 2 are $m a e=33$, rmse $=47, F B=0.19$, and $I o A=0.76$. Figures 7 and 8 with the correct calculation of $\mathrm{Q}$ are shown below.

The online version of the original article can be found under doi:10.1007/s10546-014-9907-5.

G. Casasanta $(\varangle) \cdot$ I. Pietroni $\cdot$ I. Petenko $\cdot$ S. Argentini

Institute of Atmospheric Sciences and Climate, CNR, via del Fosso del Cavaliere 100, 00133 Rome, Italy

e-mail: g.casasanta@isac.cnr.it

I. Petenko

A.M. Obukhov Institute of Atmospheric Physics, RAS, Pyzhevskiy, 3, Moscow 119017, Russia 
Fig. 7 Mixing-layer heights computed with Eq. 4 (red full line), and the GB model with fixed (green full line) and variable (blue full line) $w_{\mathrm{s}}$ values for 3 January 2012. Dots represent the experimental $h$ data estimated from sodar measurements

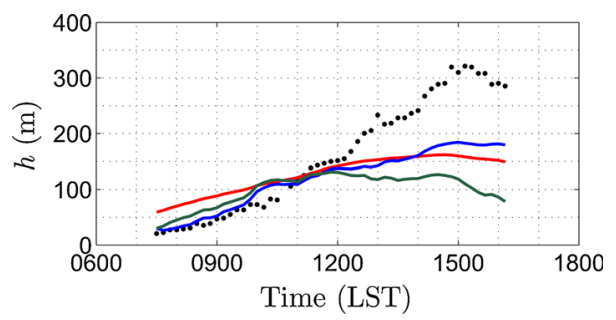

(a)

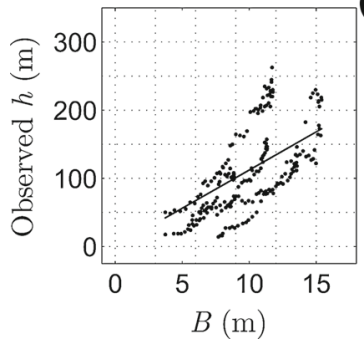

(b)

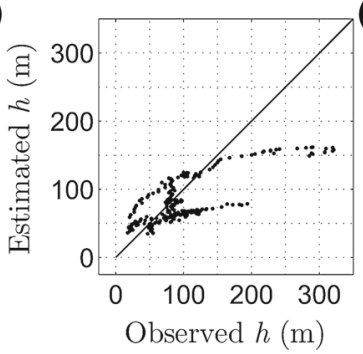

Fig. 8 Scatter plots of measured $h$ against the dimensional group $B$ (a) in Eq. 4, and against the $h$ values (b) estimated by the same equation. The full line in panel (a) and (b) represents the linear fit through origin and the bisector, respectively 